\section{Isobaric tags for relative and absolute quantitation proteomics analysis of gene regulation by SprC in Staphylococcus} \section{aureus}

\author{
Huanqiang Zhao ${ }^{\ddagger}$, Fupin $\mathrm{Hu}^{\ddagger, 2}$, Han Yang ${ }^{1}$, Baixing Ding ${ }^{2}$, Xiaogang $\mathrm{Xu}^{2}$, \\ Chunyan He', Zelin Cui', Wen Shu' \& Qingzhong Liü,
}

\begin{abstract}
Aim: To explore the complete gene networks regulated by small RNA SprC and its targets in Staphylococcus aureus. Materials \& methods: The isobaric tags for relative and absolute quantitation and bioinformatic methods were utilized to identify and analyze the target proteins affected by SprC in S. aureus N315. Results: Proteomic analysis showed that the expression of 44 proteins was modulated by SprC. Further, bioinformatic analysis displayed that these affected proteins mainly associated with metabolic and cellular process, biological regulation and catalytic activity. Conclusion: Our data provide a rich resource of SprC targets in S. aureus, although the mechanism of regulation by SprC is yet to be elucidated.
\end{abstract}

First draft submitted: 20 February 2017; Accepted for publication: 6 June 2017; Published online: 6 September 2017

Staphylococcus aureus is a ubiquitous pathogen that is the causative agent of community- and hospitalacquired infections [1]. The pathogenicity of $S$. aureus is, to a large extent, determined by its rapid adaption to diverse host microenvironments and its toxin repertoire, which involves the coordinated action of complex regulatory circuits influenced by the two-component systems, global regulatory proteins and small regulatory RNAs (sRNAs) $[2,3]$.

sRNAs are typically between 50 and 300 nucleotides in length, and most of them regulate the translation and decay of genes by binding to the target mRNAs [3,4]. In S. aureus, about 730 sRNAs have been verified, most of which currently have unknown functional, structural and mechanistic details [3,5-8]. Small pathogenicity island RNAs of $S$. aureus are expressed from genomic pathogenicity islands that present virulence and antimicrobial resistance [9]. At present, at least eight small pathogenicity island RNAs (SprA-G and X) are found [9,10], and some of them have been investigated widely. $S p r A 1_{A S}$ occludes translation initiation signals through base pairing to repress the translation of the SprA1-encoded cytolytic peptide [11]. SprD was identified as critical to the expression reduction of the Sbi immune-evasion molecule and the virulence increase of $S$. aureus [12]. SprX (alias RsaOR) was reported to possess a major role in glycopeptides resistance and virulence gene expression [6,10]. SprC negatively modulates the expression of the staphylococcal autolysin, reduces $S$. aureus phagocytosis by human leucocyte and decreases the virulence of bacteria, however, it is adverse for $S$. aureus resistance to oxidative stress [13].

'Department of Clinical Laboratory, Shanghai General Hospital, Shanghai Jiaotong University School of Medicine, Shanghai, China ${ }^{2}$ Institute of Antibiotics, Huashan Hospital, Fudan University, Shanghai, China

*Author for correspondence: Tel.: +86 213779 8212; Fax: +86 216324 0825; jiaodamedicine@foxmail.com

${ }^{\ddagger}$ Authors contributed equally

\section{KEYWORDS}

- iTRAQ $\bullet$ proteomics $\bullet$ SprC

- sRNA • Staphylococcus aureus 
In view of the different roles of SprC, in this study we applied isobaric tags for relative and absolute quantitation (iTRAQ) to explore the global view of the changes in protein expression and intercommunication in $s p r C$ deletion mutant of $S$. aureus N315 and find more targets of SprC.

\section{Materials \& methods}

- Strains \& plasmids

The bacterial strains and plasmids are listed in Table 1. S. aureus strains were cultured at $37^{\circ} \mathrm{C}$ in Tryptic Soy Broth (TSB; Oxoid, Basingstoke, UK) or on Tryptic Soy Agar (Oxoid); when necessary, the media were supplemented with either chloramphenicol $(10 \mu \mathrm{g} / \mathrm{ml})$ or anhydrotetracycline hydrochloride $(50 \mathrm{ng} / \mathrm{ml})$. Escherichia coli strains were grown at $37^{\circ} \mathrm{C}$ in Luria-Bertani liquid medium or on Luria-Bertani agar containing a suitable antibiotic: ampicillin or kanamycin $(50 \mu \mathrm{g} / \mathrm{ml})$, as appropriate.

Genomic DNA was extracted by TIANamp Bacterial DNA Kit (Tiangen Biotech Co., Ltd., Beijing, China). Plasmids from E. coli were extracted using a plasmid purification kit (Promega, WI, USA); for plasmid extraction of S. aureus, the cells were predigested with a digestion buffer with $40 \mathrm{U} / \mathrm{ml}$ lysostaphin, $10 \mathrm{mg} / \mathrm{ml}$ lysozyme and 10\% (v/v) glycerol.

\section{- Construction of the isogenic sprC deletion mutant strains}

To inactivate the $s p r C$ gene, DNA fragments of 940-bp upstream and 930-bp downstream of $\operatorname{spr} C$ were amplified from $S$. aureus strain N315 chromosomal DNA, and then cloned into the BamHI-EcoRI and EcoRI-HindIII sites of plasmid pET28a, respectively. The resulting plasmid pET28a $\Delta \operatorname{spr} C$ was aimed to provide DNA templates containing the upstream and downstream of $\operatorname{spr} C$ gene. Using primers $s p r C$ att1 and $s p r C$-att2, another PCR reaction was performed with the plasmid pET28a $\Delta s p r C$ as a template. The PCR products with attB sites at both ends were used for recombination with temperature-sensitive plasmid pKOR1, generating plasmid pKOR $1 \Delta s p r C$. The $\mathrm{pKOR} 1 \Delta s p r C$ was transformed first into $S$. aureus strain RN4220, and then into $S$. aureus N315 through electroporation. The procedure for homologous recombination was performed as previously described [16]. The deletion of $\operatorname{spr} C$ was confirmed by PCR and sequencing. For restoring the SprC activity, primers $s p r C \mathrm{r}$-up-EcoRI and sprCr-down-BamHI were designed to amplify a 236-bp fragment which contained the $s p r C$ gene and its own putative promoter region. Then the PCR products were digested and

\begin{tabular}{|c|c|c|}
\hline Strain or plasmid & Genotypes or characteristics & Ref. \\
\hline \multicolumn{3}{|c|}{ Staphylococcus aureus } \\
\hline RN4220 & $\begin{array}{l}\text { Restriction-negative strain that accepts foreign } \\
\text { DNA, 8325-4 derivative }\end{array}$ & [14] \\
\hline N315 & $\begin{array}{l}\text { MRSA strain isolated from the pharyngeal smear of } \\
\text { a Japanese patient }\end{array}$ & [15] \\
\hline N315 $\Delta$ sprC & Isogenic sprC deletion mutant of N315 & This study \\
\hline \multicolumn{3}{|l|}{ Escherichia coli } \\
\hline $\mathrm{DH} 5 \alpha$ & $\begin{array}{l}\text { A host strain for cloning, supE44 } \Delta / a c U 169 \text { (80dlacZ } \\
\Delta \mathrm{M} 15) \text { hsdR17 recA1 endA1 gyrA96 thi-1 relA1 }\end{array}$ & Tiangen company \\
\hline \multicolumn{3}{|l|}{ Plasmids } \\
\hline pKOR1 & $\begin{array}{l}\text { Temperature-sensitive vector for allelic } \\
\text { replacement via } \lambda \text { recombination and } \mathrm{ccdB} \\
\text { selection }\end{array}$ & [16] \\
\hline pKOR1 1 sprC & pKOR1 derivative for allelic replacement of sprC & This study \\
\hline pET28a & Bacterial expression vector with T7lac promoter & Novagen company \\
\hline $\mathrm{pET} 28 \mathrm{a} \Delta s p r C$ & $\begin{array}{l}\text { pET28a vector containing the } 940-b p \text { upstream } \\
\text { genomic sequence of } s p r C \text { and its } 930 \text {-bp } \\
\text { downstream sequence, excluding the } s p r C \text { gene } \\
\text { sequence }\end{array}$ & This study \\
\hline pOS1 & $\begin{array}{l}\text { Escherichia coli-staphylococcal shuttle cloning } \\
\text { plasmid }\end{array}$ & [17] \\
\hline pOS1sprC & $\begin{array}{l}\text { pOS1 with } \operatorname{sprC} \text { under the control of the putative } \\
\text { natural } \operatorname{sprC} \text { promoter }\end{array}$ & This study \\
\hline
\end{tabular}


cloned into plasmid pOS1. Primers used for cloning were listed in Table 2.

\section{- Quantitative real-time PCR}

Overnight cultures were diluted 1:100 into $50 \mathrm{ml}$ fresh TSB and incubated at $37^{\circ} \mathrm{C}$ with agitation and stopped at various phases of growth. Cells were then collected by centrifugation at $10,000 \times g$ for $10 \mathrm{~min}$, resuspended in $150-\mu \mathrm{l}$ TE buffer (10 mM Tris-HCl, 1 mM EDTA, pH 8.0) containing $10-\mu \mathrm{g}$ lysostaphin and $200-\mu \mathrm{g}$ proteinase $\mathrm{K}$ and incubated for $30 \mathrm{~min}$ at $37^{\circ} \mathrm{C}$. The subsequent procedure for RNA extraction was carried out by a MiniBEST Universal RNA Extraction Kit (TaKaRa, Dalian, China) according to the manufacturer's instructions. The purified RNA was quantified using a NanoDrop spectrometer (Thermo Fisher Scientific, MA, USA). The primer pairs used in quantitative real-time PCR were listed in Table 2. Total RNA was reverse transcribed into cDNA using the PrimeScript ${ }^{\mathrm{TM}} \mathrm{RT}$ reagent Kit with gDNA Eraser ( $\mathrm{TaKaRa}$ ), according to the manufacturer's protocol. The resulting $\mathrm{cDNAs}$ were stored at $-20^{\circ} \mathrm{C}$ until they were required. The quantitative real-time PCR was carried out in $20-\mu l$ reaction mixture containing $10-\mu \mathrm{l} 2 \times$ SYBR Premix Ex Taq (Tli RNaseH Plus, TaKaRa), 0.4- $\mu$ l PCR forward primer $(10 \mu \mathrm{M}), 0.4-\mu \mathrm{l}$ PCR reverse primer $(10 \mu \mathrm{M}), 0.4-\mu l$ ROX Reference Dye II (50x), 2- $\mu \mathrm{l} \mathrm{cDNA}$ and 6.8- $\mu \mathrm{l} \mathrm{dH}_{2} \mathrm{O}$ (TaKaRa). The cycling parameters were incubated at $95^{\circ} \mathrm{C}$ for $30 \mathrm{~s}$, and then 40 cycles consisting of $95^{\circ} \mathrm{C}$ for $5 \mathrm{~s}$ and $60^{\circ} \mathrm{C}$ for $34 \mathrm{~s}$, followed by a dissociation step of $95^{\circ} \mathrm{C}$ for $15 \mathrm{~s}, 60^{\circ} \mathrm{C}$ for $1 \mathrm{~min}$ and $95^{\circ} \mathrm{C}$ for $15 \mathrm{~s}$ on Applied Biosystems 7500
Real Time PCR System (Applied Biosystems, CA, USA). The housekeeping gene 16S rRNA was selected as the internal control for normalization. The primer efficiency of the amplification for each gene was assessed by melting curve analysis.

\section{- Isobaric tags for relative $\&$ absolute quantitation \\ Sample preparation}

$S$. aureus strains N315 and N315 $\Delta \operatorname{sprC}$ were maintained in TSB and grown to late logarithmic growth phase at $37^{\circ} \mathrm{C}$ with constant agitation at 150 r.p.m. under aerobic conditions. The cells were collected by centrifugation and washed twice with phosphate-buffered saline. SDT lysis buffer (4\% SDS, 1 mM DL-Dithiothreitol, 100 $\mathrm{mM}$ Tris- $\mathrm{HCl}, \mathrm{pH} 7.6)$ was added to the samples. The cells were then ultrasonically disrupted ten-times for $10 \mathrm{~s}$ intervals with $15 \mathrm{~s}$ rest periods, followed by boiling water bath for $15 \mathrm{~min}$. The supernatant was filtered with $0.22 \mu \mathrm{m}$ filter. And the BCA Protein Assay Kit (Bio-Rad, CA, USA) was used for the quantification of filtrate.

\section{Enzyme digestion \& iTRAQ labeling}

A total of $200 \mu \mathrm{g}$ of proteins for each sample were taken and combined with DL-Dithiothreitol to a final concentration of $100 \mathrm{mM}$. The mixtures were put in a boiling water bath for $5 \mathrm{~min}$, and cooled to room temperature. Then 200- $\mu$ l urea lysis buffer ( $8 \mathrm{M}$ urea, $150 \mathrm{mM}$ Tris- $\mathrm{HCl}$, $\mathrm{pH}$ 8.0) was added for removing the detergent. The mixtures were transferred into an ultrafiltration device (Microcon units, $10 \mathrm{kD}$ ) followed by centrifugation at $14,000 \times g$ for

\section{Table 2. Oligonucleotides used in this study.}

Primer name Sequence

\begin{tabular}{ll} 
For isogenic sprC deletion mutant & \\
sprC-up-BamHI & CGCggatccATTACCTCCAATGTTATATCC \\
sprC-up-EcoRI & CCGgaattcATTTTTAAAGTGAAATTTTAGTTC \\
\hline sprC-down-EcoRI & CCGgaattcTCGTTGACTTATTTATATTATAAT \\
sprC-down-HindIII & CCCaagcttTCTAAACCAAATATAGTATAGC \\
sprC-att1 & ggggacaagtttgtacaaaaaagcaggctATTACCTCCAATGTTATATCC \\
sprC-att2 & ggggaccactttgtacaagaaagctgggtTCTAAACCAAATATAGTATAGC \\
For sprC complementation & \\
sprCr-up-EcoRI & CCGgaattCAAGTATTGAAAAATAAAATATTT \\
sprCr-down-BamHI & CGCggattCAACATATATATATTTACTATGAAC \\
For qRT-PCR & \\
sprC-F & CCATGCGTGGACAGTAAAACG \\
sprC-R & ACTGAAGCTTCTACTCTCATGGC \\
\hline aRT-PCR: Quantitative real-time PCR. & \\
\hline
\end{tabular}


$15 \mathrm{~min}$. The precipitates were resuspended in $200-\mu \mathrm{l}$ urea lysis buffer and the ultrafiltration step was repeated. Then $100-\mu l$ iodoacetamide (100 mM iodoacetamide in urea lysis buffer) was added to the samples and the mixtures were incubated for $30 \mathrm{~min}$ in darkness. After centrifugation, the precipitates were washed two-times with $100 \mu$ l of urea lysis buffer, and then $100 \mu \mathrm{l}$ of dissolution buffer (DS buffer) twice. Finally, the precipitates were reconstituted in $40-\mu$ trypsin buffer $(4-\mu \mathrm{g}$ trypsin in 40- $\mu$ l dissolution buffer), agitated at 600 r.p.m. for $1 \mathrm{~min}$ and then incubated overnight at $37^{\circ} \mathrm{C}$. The filtrates were collected in fresh collection tubes after centrifugation. The peptides of each sample were desalted on C18 Cartridges (Sigma-Aldrich, $\mathrm{MO}$, USA), concentrated by vacuum centrifugation and reconstituted in $40 \mu \mathrm{l}$ of $0.1 \%(\mathrm{v} / \mathrm{v})$ formic acid. Peptide content was estimated by measuring the optical density at $280 \mathrm{~nm}$. After quantification, $100 \mu \mathrm{g}$ of peptide mixture of each sample was labeled using an iTRAQ 8-plex Multiplex kit (Applied Biosystems) according to the manufacturer's instructions. All the experiments for each sample were performed with three biological replicates. iTRAQ reagents 113 , 114 and 115 were used for wild-type N315 strain and reagents 116, 117 and 118 were applied for $\mathrm{N} 315 \Delta \operatorname{spr} C$ mutant strain.

\section{Peptide fractionation with strong cation exchange chromatography}

iTRAQ-labeled peptides were fractionated by strong cation exchange chromatography using the AKTA Purifier 100 (GE Healthcare, Little Chalfont, UK). The dried-labeled samples were resuspended and acidified with buffer $\mathrm{A}$ (10 $\mathrm{mM} \mathrm{KH}_{2} \mathrm{PO}_{4}$ and 25\% acetonitrile, $\mathrm{pH}$ $3.0)$ and then loaded onto a $4.6 \times 100 \mathrm{~mm}$ PolySulfoethyl column (5 $\mu \mathrm{m}, 200 \AA$ A PolyLC, MD, USA). During the strong cation exchange separation, the peptides were eluted at a flow rate of $1 \mathrm{ml} / \mathrm{min}$ with a gradient of $0-8 \%$ buffer B $\left(500 \mathrm{mM} \mathrm{KCl}, 10 \mathrm{mM} \mathrm{KH}_{2} \mathrm{PO}_{4}\right.$ and $25 \%$ acetonitrile, $\mathrm{pH} 3.0$ ) for $22 \mathrm{~min}, 8-52 \%$ during $22-47 \mathrm{~min}, 52-100 \%$ during $47-50 \mathrm{~min}$, $100 \%$ during $50-58 \mathrm{~min}$ and $0 \%$ after $58 \mathrm{~min}$. The fractions were collected every $1 \mathrm{~min}$ and the elution was monitored by absorbance at $214 \mathrm{~nm}$. The collected fractions were lyophilized prior to desalination in a C18 Cartridge (Sigma-Aldrich) and concentrated by vacuum centrifugation for subsequent liquid chromatography-tandem mass spectrometry analysis.

\section{Liquid chromatography-tandem mass} spectrometry

An Easy nLC system (Thermo Fisher Scientific) was used for liquid separation of each fraction. The peptide mixtures were loaded onto a reverse phase trap column $(2 \mathrm{~cm} \times 100 \mu \mathrm{m}, 5 \mu \mathrm{m})$ connected to the $\mathrm{C} 18$-reversed phase analytical column $(75 \mu \mathrm{m} \times 10 \mathrm{~cm}, 3 \mu \mathrm{m})$. Buffer A $(0.1 \%$ formic acid) was used for equilibration of chromatographic columns and buffer B (84\% acetonitrile and $0.1 \%$ formic acid), with a linear gradient at a flow rate of $300 \mathrm{nl} / \mathrm{min}$, was utilized for mixture separation. The peptides were subjected to nano-electrospray ionization followed by tandem mass spectrometry (MS/MS) in a Q-Exactive mass spectrometer (Thermo Fisher Scientific) coupled to Easy nLC. The mass spectrometer was operated in positive-ion detection mode, and the most abundant precursor ions from the scanning range of $300-1800 \mathrm{~m} / \mathrm{z}$ were chosen to obtain MS data. Automatic gain control target was set to $3 \mathrm{e} 6$ and a first-order maximum injection time was $10 \mathrm{~ms}$. The dynamic exclusion duration was $40 \mathrm{~s}$. Survey scans were obtained at a resolution of 70,000 at $\mathrm{m} / \mathrm{z} 200$ and resolution for higher-energy collisional dissociation (HCD) spectra was set to 17,500 at $\mathrm{m} / \mathrm{z} 200$. Other parameters were as follows: the isolation window was $2 \mathrm{~m} / \mathrm{z}$, the second-order maximum injection time was $60 \mathrm{~ms}$, normalized collision energy was $30 \mathrm{eV}$ and the underfill ratio was defined as $0.1 \%$.

\section{Data analysis}

Database searches and quantitative analyses were carried out using Mascot engine (Matrix Science, London, UK; version 2.2) embedded into Proteome Discoverer 1.4 (Thermo Fisher Scientific). The proteins sequence of $S$. aureus 2926 in the UniProt knowledge base [18] was selected as a reference. For proteins identification, a peptide mass tolerance of \pm 20 p.p.m. and a fragment mass tolerance of $0.1 \mathrm{Da}$ were permitted with allowance for two missed cleavage in the trypsin digests. Fixed modifications included carbamidomethyl (C), iTRAQ 4/8plex (N-term) and iTRAQ 4/8plex (K), while oxidation $(\mathrm{M})$ and iTRAQ 4/8plex (Y) were tested as potential variable modifications. Only proteins that appeared in more than two biological replicates were included in the analysis. The quantitative protein ratios were normalized by the median ratio in Mascot and the median protein ratio should be 1 after the normalization. 
Proteins with a 1.2-fold change and a two-tailed p-value $<0.05$ were considered significant. The BLAST2GO [19] was used to extract gene ontology (GO) terms and add function annotations to the target proteins. The Kyoto Encyclopedia of Genes and Genomes (KEGG) Automatic Annotation Server [20] was utilized to identify the metabolic pathways and functional groups and STRING (version 10.0) was applied to explicitly show the differentially expressed proteins in the context of protein-protein interaction networks. The subcellular localization distribution of proteins was predicted with PSORTb v3.0.2.

\section{Statistical analyses}

Statistically significant differences were determined by Student's $t$-test using SAS 9.3 for Windows software (SAS Institute Inc., NC, USA) and all tests were considered to be statistically significant when $\mathrm{p}<0.05$.

\section{Results}

\section{- SprC expression during growth}

The growth curves of wild-type N315 and $\mathrm{N} 315 \Delta \operatorname{spr} C$ mutant strains were nearly the same in TSB broth (Figure 1A). These results indicated the knockout of $s p r C$ did not affect $S$. aureus proliferation. The data of the SprC expression during the growth of N315 displayed that SprC was already expressed during the early exponential phase and decreased slightly at the middle exponential phase. Subsequently, the gradual increasing transcription of SprC was monitored at late exponential and stationary growth phases (Figure 1B).

\section{- Differentially expressed proteins between N315 \& N315 $\Delta$ sprC mutant strains}

Proteins extracted from N315 and N315 ssprC mutant strains during the late exponential phase were analyzed and three repetitions were set for each strain. A total of 1051 proteins were identified from the original mass spectrometry data. Among these proteins, 44, meeting the criteria as depicted above under the 'Data analysis', were revealed to be differentially expressed (Table 3 ). Further analysis showed that eight proteins were higher in N315 $\Delta p \operatorname{sp}$ mutant strains compared with the parent strain N315 with the fold change ranging from 1.21 to 2.93 (Table 3). Of note, two proteins presented at the highest concentration in $\operatorname{sprC}$ mutant were LukE (A0A0E1VG99) and LukD (A0A0E1VQ50), which had fold change values of 2.75 and 2.93, respectively. In contrast, 36 proteins were measured at decreased levels (Table 3), with fold values ranging from -1.2 to -3.16, of which three (DNA-binding helix-turnhelix protein, a SNARE-like domain protein and an EDD domain [common to three different folds: mannose transporter EIIA domain, dihydroxyacetone kinase, and DegV-like protein fold] protein of DegV family) were observed to have the greatest degree of fold change $(-3.16$, -2.69 and -2.28 , respectively; Table 3$)$. The MS/MS spectra of the representative peptides of
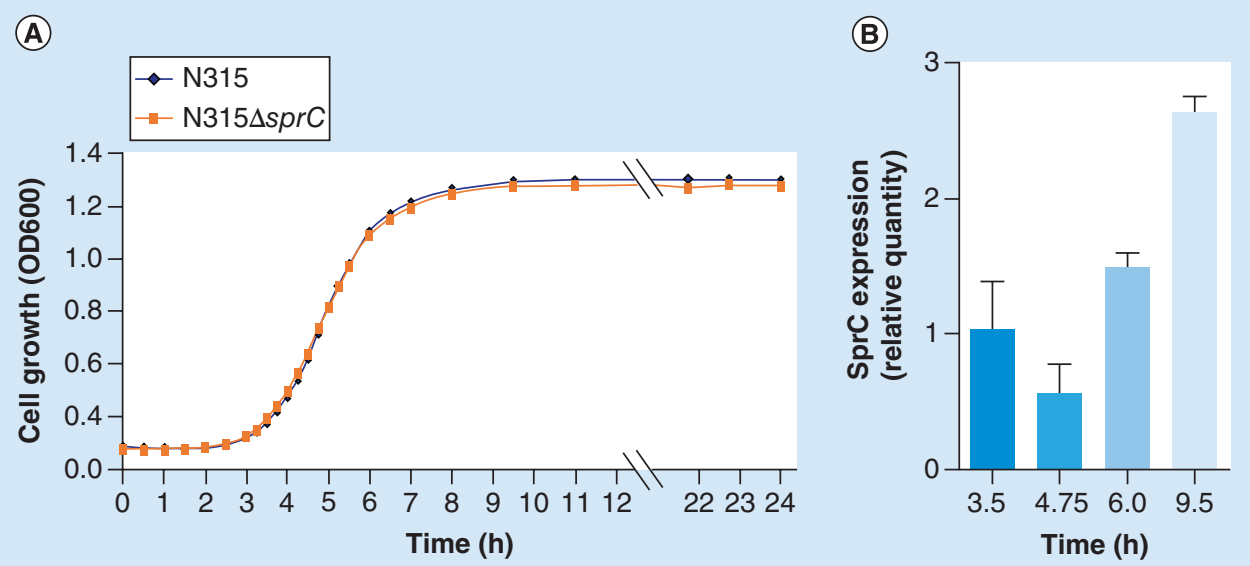

Figure 1. SprC RNA expression profile in Staphylococcus aureus N315 strain. (A) The growth curves of N315 and N315 $\Delta$ sprC mutant. (B) The expression of SprC of S. aureus N315 at four time points representing early exponential phase, middle exponential phase, late exponential phase and stationary growth phase.

OD: Optical density. 


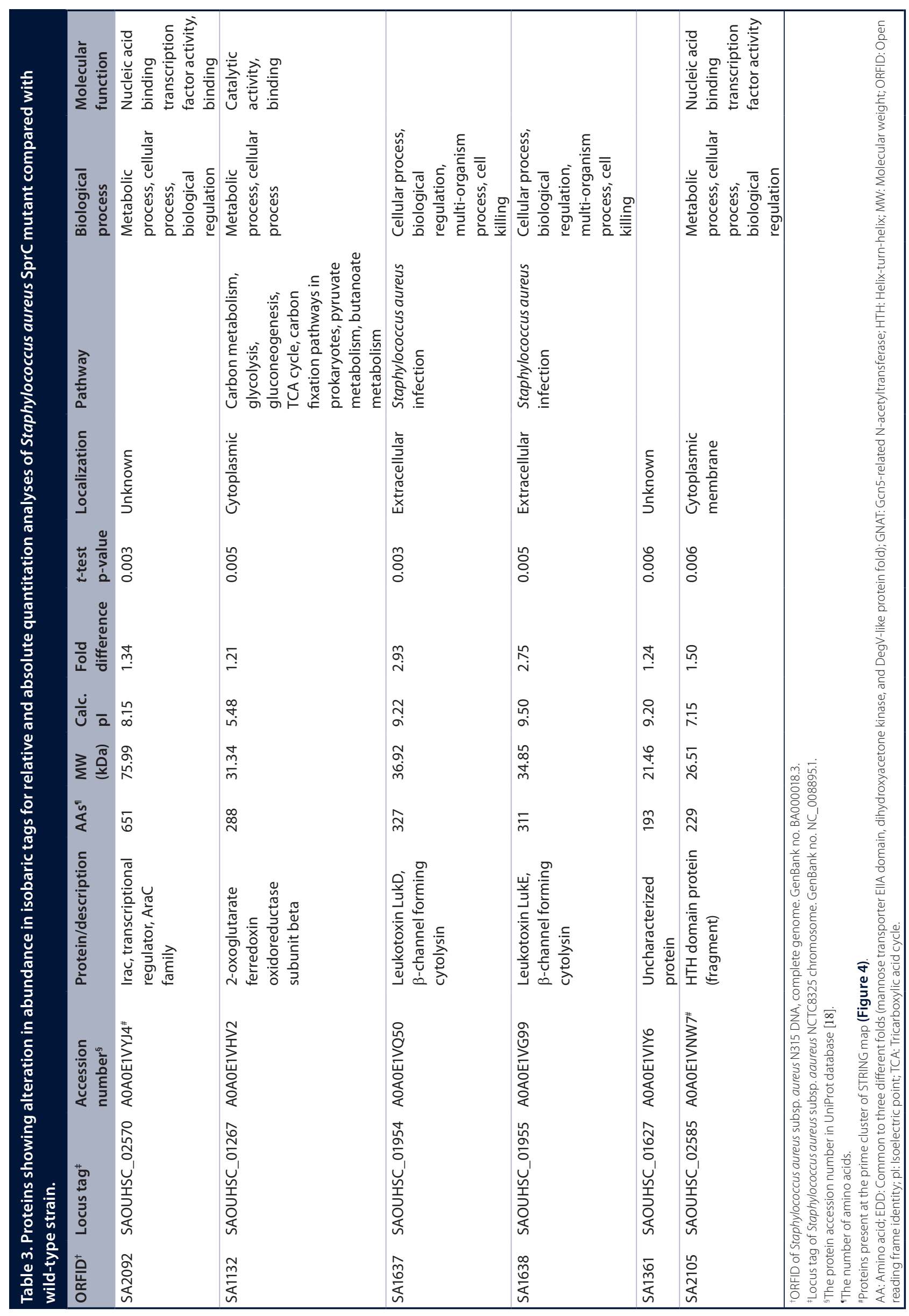




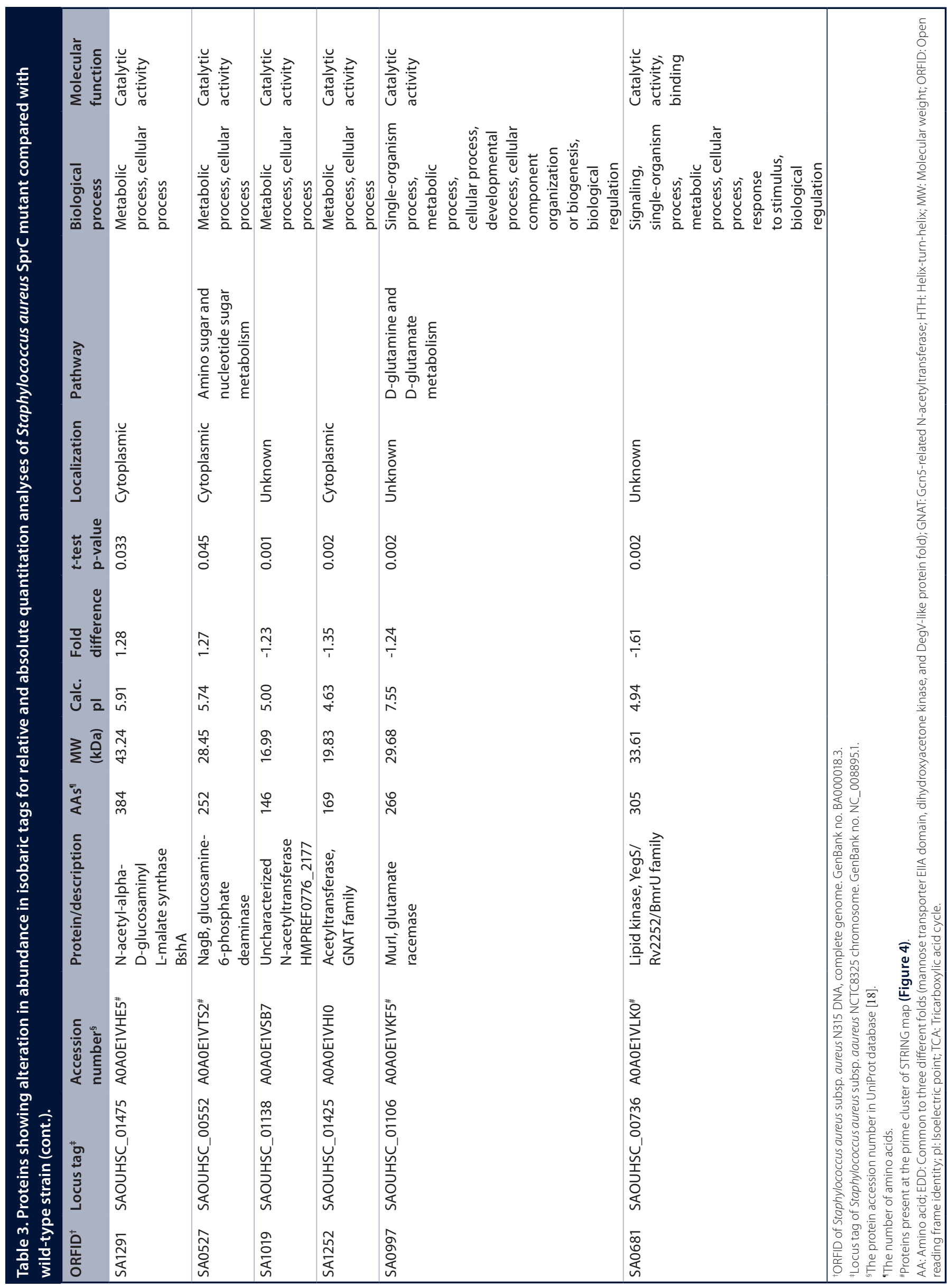




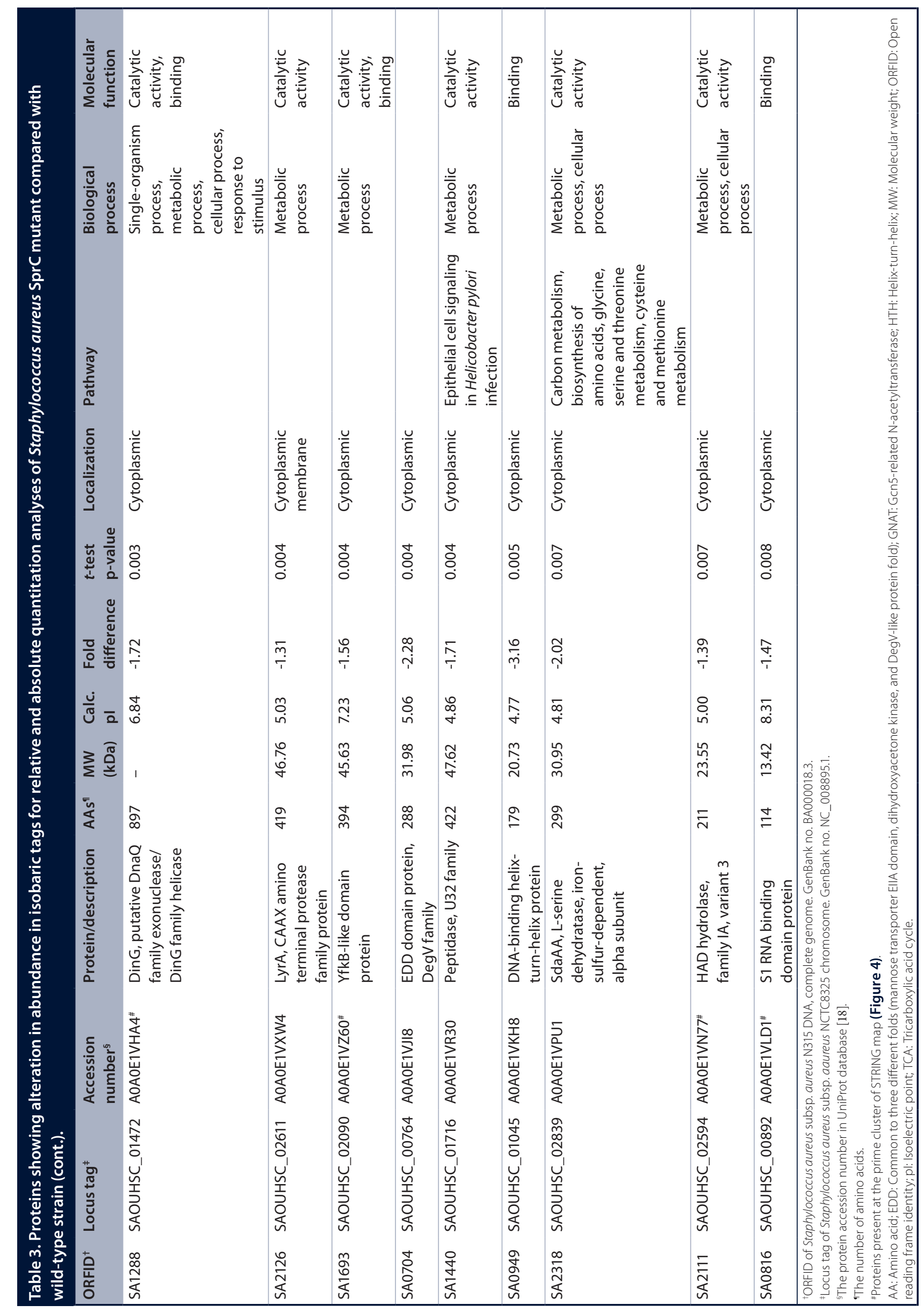




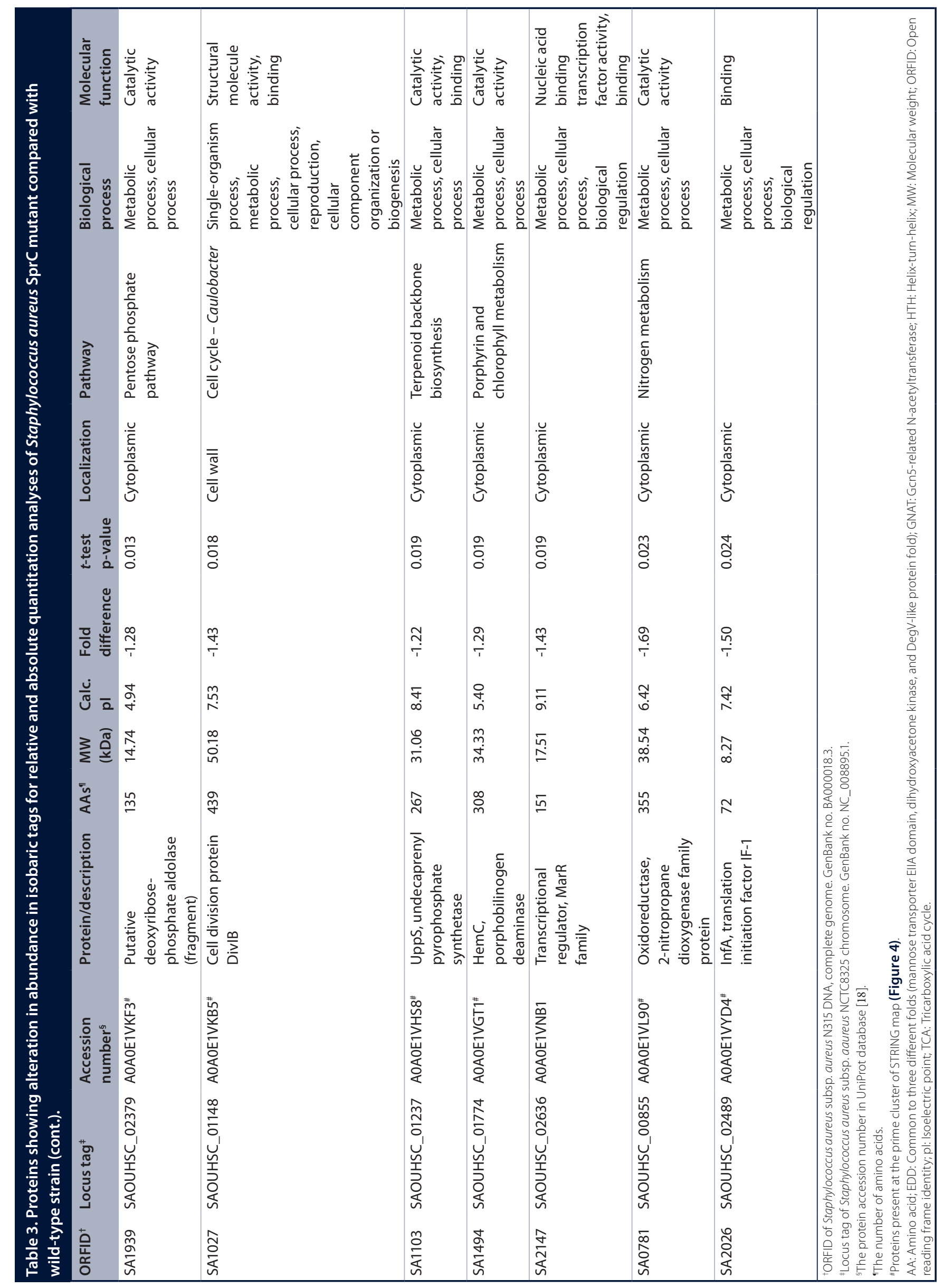




$$
\mid
$$




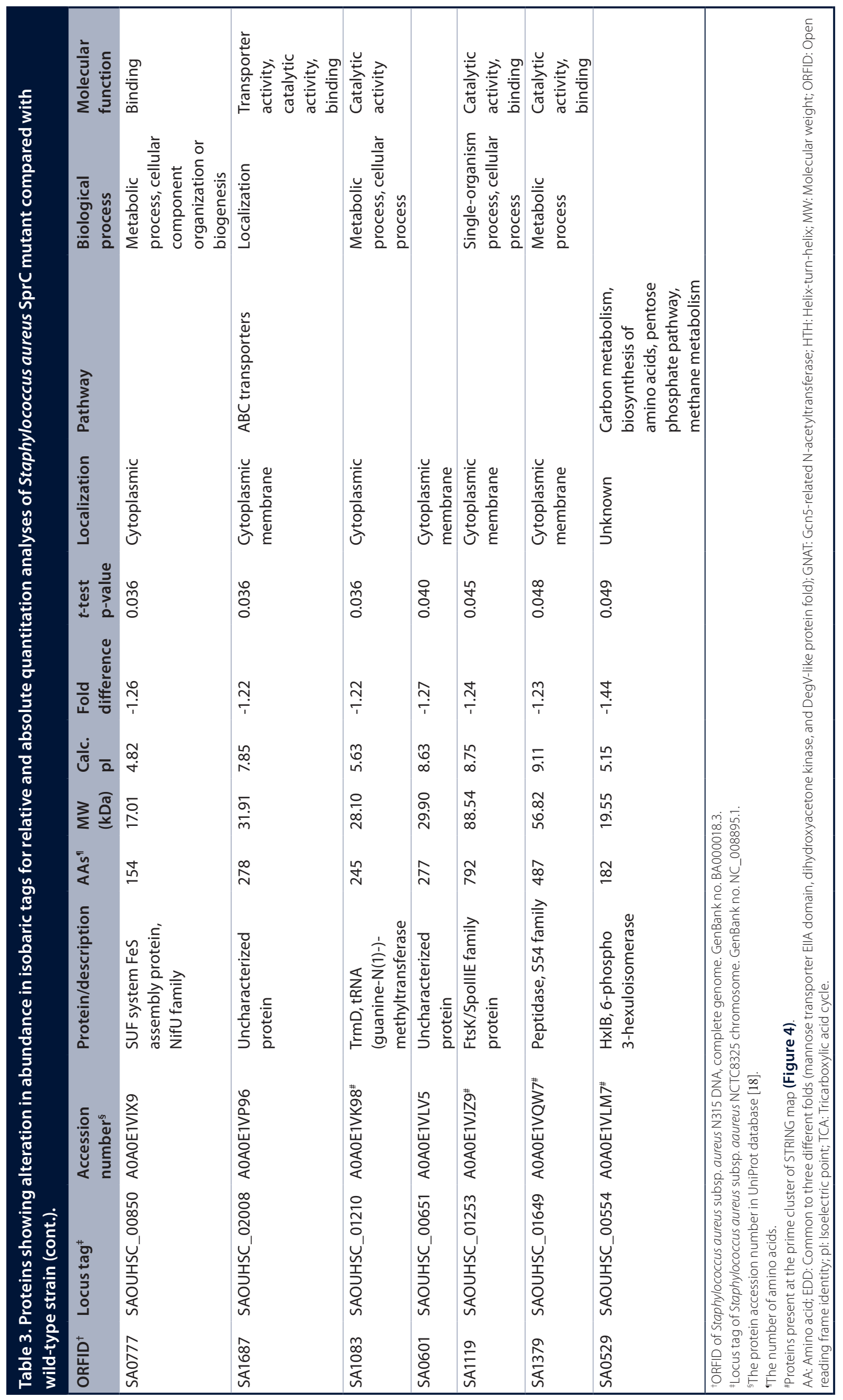


A0A0E1VYJ4 (transcriptional regulator, AraC family) and A0A0E1VKB5 (cell division protein DivIB) are shown in Figure 2.

\section{- Global functional classification of differentially expressed proteins}

The functions of 44 affected proteins were categorized according to the GO annotation based on the biological functional hierarchy. GO analysis revealed that affected proteins were associated with 12 biological processes, which mainly included metabolic process (GO: 0008152, 33.7\%), cellular process (GO: 0009987, 30.6\%) and biological regulation (GO: 0065007, 10.2\%; Figure 3A). The GO classification of identified proteins according to cellular components indicated that $46.9 \%$ of differentially expressed proteins are involved in cell (GO: 0005623), 21.9\% in both membrane (GO: 0016020) and macromolecular complex (GO: 0032991) and 9.4\% in extracellular region (GO: 0005576; Figure 3B). Functional classification according to molecular functions indicated that $56.6 \%$ are involved in catalytic activity (GO: 0003824), 34\% in binding (GO: 0005488), 5.7\% in nucleic acid binding transcription factor activity (GO: 0001071) and 1.9\% in both structural molecule activity (GO: 0005198) and transporter activity (GO: 0005215; Figure 3C). All of the above signified the multifunctional role of SprC.

\section{- Subcellular distribution of the differentially expressed proteins}

As shown in Figure 4 and Table 3, 1 (2.3\%), 22 (50.0\%), 9 (20.5\%), 2 (4.5\%) and $10(22.7 \%)$ proteins were classified as cell wall, cytoplasmic, cytoplasmic membrane, extracellular and unknown proteins, respectively. The affected proteins are especially enriched with cytoplasmic and cytoplasmic membrane proteins, suggesting the SprC's significant role in the formation of cytoplasm.

\section{- KEGG pathway enrichment analysis}

By mapping the differentially expressed genes to KEGG pathways, a total of 21 signal/metabolic

(A)

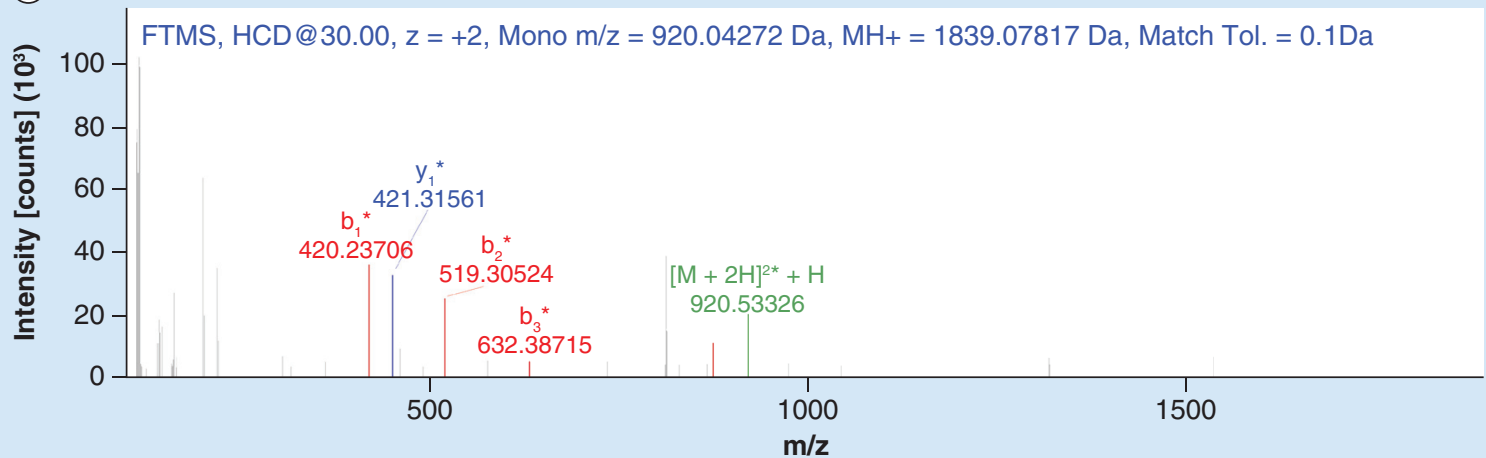

(B)

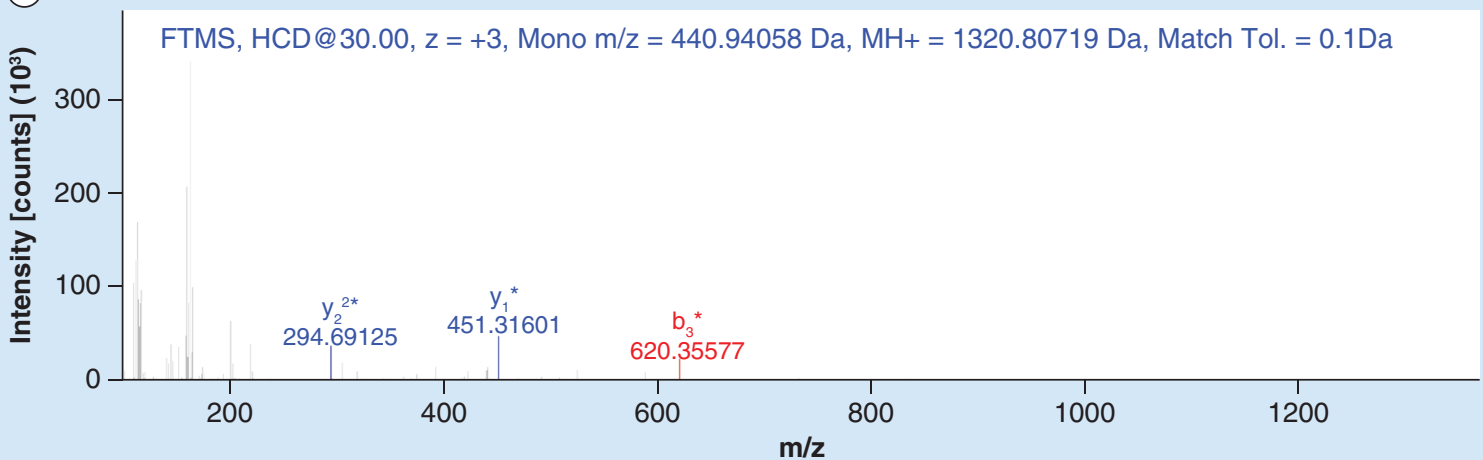

Figure 2. Representative tandem mass spectrometry spectra of isobaric tags for relative and absolute quantitation labeling peptides. (A) Tandem mass spectrometry spectra of the peptide A0A0E1VYJ4 (transcriptional regulator, AraC family); (B) Tandem mass spectrometry spectra of the peptide A0A0E1VKB5 (cell division protein DivIB).

FTMS: Fourier transform mass spectrometer; HCD: Higher-energy collisional dissociation. 
(A)

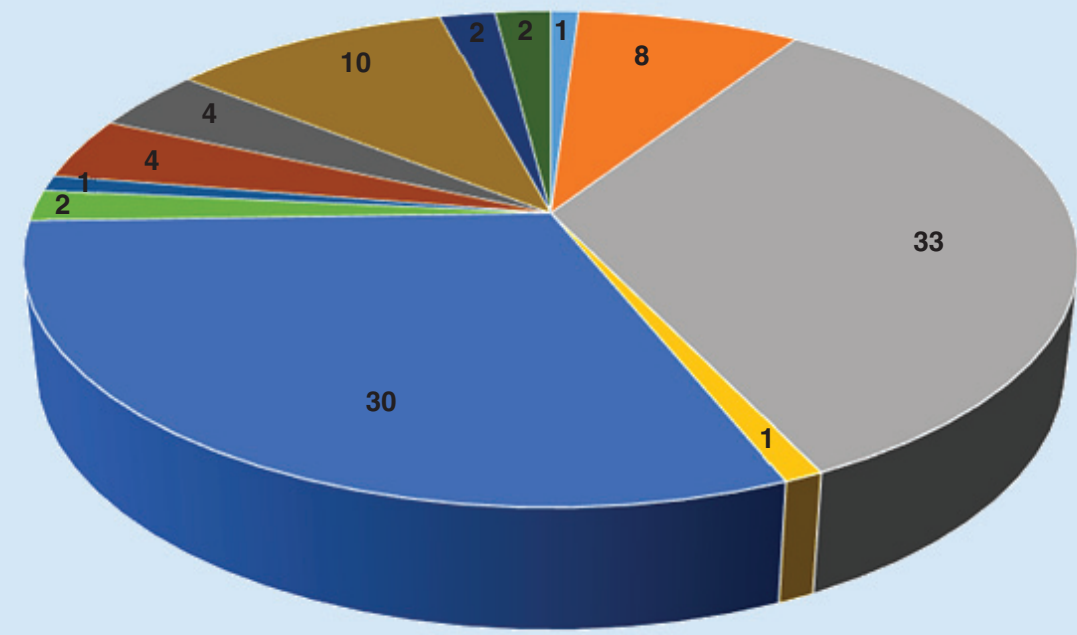

(B)

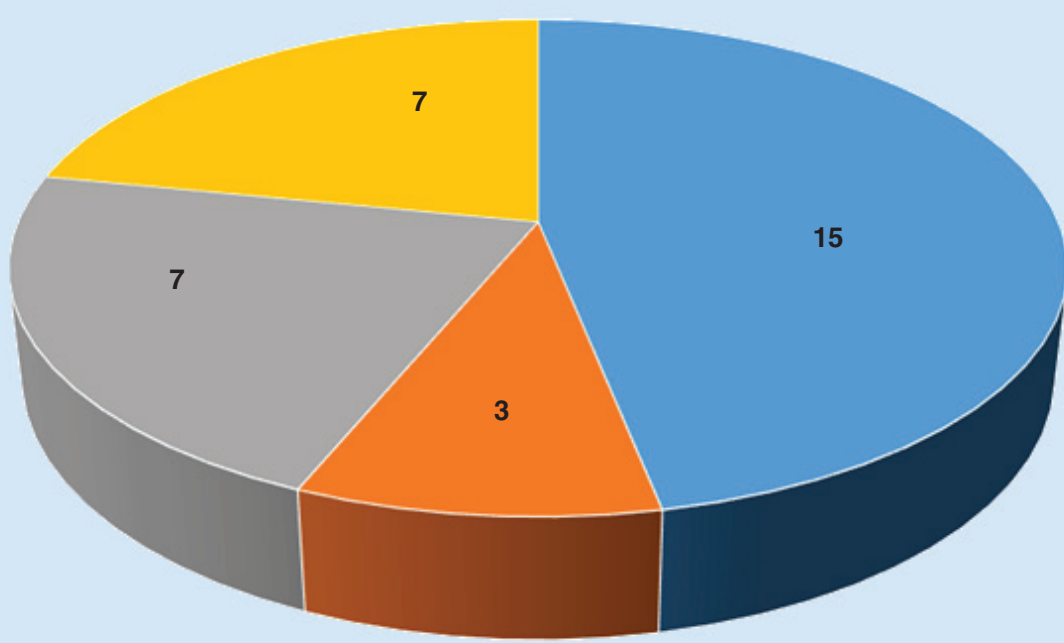

(C)

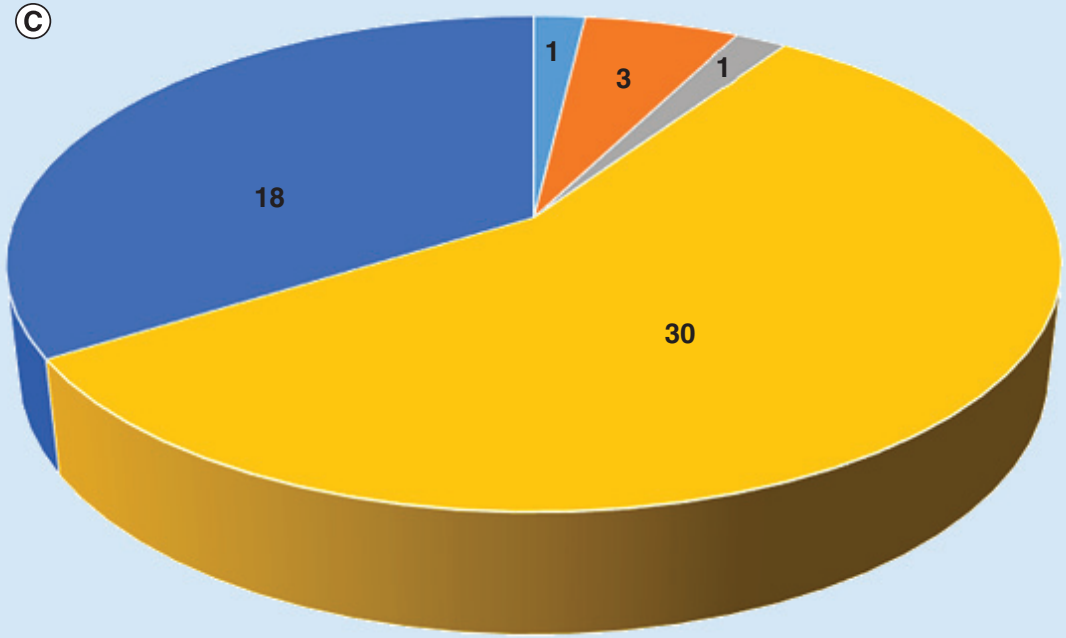

\section{Biological process}

- Signaling (GO: 0023052)

- Signaling-organism process (GO: 0044699)

- Metabolic process (GO: 0008152)

= Localization (GO: 0051179)

- Cellular process (GO: 0009987)

- Developmental process (GO: 0032502)

- Reproduction (GO: 0000003)

- Response to stimulus (GO: 0050896)

Cellular component organization or

biogenesis (GO: 0071840)

- Biological regulation (GO: 0065007)

- Multi-organism process (GO: 0051704)

- Cell killing (GO: 0001906)

Cellular component
- Cell (GO: 0005623)
- Extracellular region (GO: 0005576)
- Membrane (GO: 0016020)
- Macromolecular
complex (GO: 0032991)

\section{Molecular function}

- Structural molecule activity (GO: 0005198)

- Nucleic acid binding transcription factor activity (GO: 0001071)

- Transporter activity (GO: 0005215)

. Catalytic activity (GO: 0003824)

- Binding (GO: 0005488) 
Figure 3. Classification of the differentially expressed proteins according to biological functions (see previous page). The biological processes, cellular components and molecular functions of the identified significant proteins influenced by SprC were classified by the Gene Ontology database. GO: Gene ontology.

pathways related to 21 differentially expressed proteins were extracted. A large number of proteins were concerned with carbon metabolism (ko01200), biosynthesis of amino acids (ko01230), pentose phosphate pathway (ko00030) and S. aureus infection (ko05150). Each remaining pathway was related to only one affected protein (Figure 5 \& Table 3).

\section{- Protein-protein interaction network analysis using STRING}

Interaction knowledge from STRING suggested that SprC may have the potential to interact with distinct genes. The STRING map of the proteins affected by SprC showed one prime cluster including 26 proteins, while the remaining proteins presented sporadic relations. The proteins clustered are mainly involved in metabolic process $(80.8 \%, 21 / 26)$, cellular process $(73.1 \%, 19 / 26)$ and catalytic activity $(69.2 \%, 18 / 26)$. Moreover, cytoplasm was the leading subcellular location of proteins belonging to this cluster $(53.8 \%, 14 / 26$; Figure 6 \& Table 3 ).

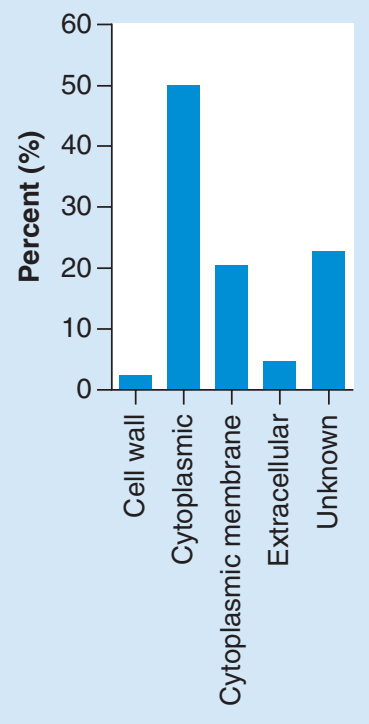

Figure 4. Localization distribution of differentially expressed proteins predicted by PSORTb v3.0.2.

\section{Discussion}

It is generally known that staphylococcal pathogenicity is determined by a variety of virulence factors rather than a single toxin. The virulence factors, including surface and extracellular molecules, enable bacteria to adhere to host cells, damage tissue, evade the immune system and consequently, cause acute infections. In recent years, various proteomic techniques have become powerful scientific tools to explore the interactions among virulence factors responsible for the complex pathogenicity of bacteria. iTRAQ is an excellent experimental technique for quantitative mass spectrometry in proteome research and provides a strategy to allow the identification and comparison of protein expression in different strains [21]. In the present study, 44 differentially expressed proteins, primarily impacting bacterial functions, were identified by the iTRAQ method and bioinformatic analysis uncovered that the proteins influenced by SprC were principally involved with metabolic and cellular process, biological regulation and catalytic activity.

So far, $S$. aureus sRNAs have been shown to be able to regulate bacterial pathogenesis, antibiotic resistance and host-pathogen interactions in a dynamic manner [3,22]. $\operatorname{spr} C$, situated next to Leucocidin ED (LukED), shows large variations in expression among different $S$. aureus strains. For example, its expression is abundant in strain N315, whereas it is almost switched off in strains MRSA252 and 502A [9], suggesting that SprC may be involved in the regulation of staphylococcal virulence. Therefore, it is necessary to identify comprehensive gene networks modulated by SprC. Bacterial growth is most active in logarithmic phase that is involved with DNA synthesis, coupling with transcription and translation and synthesizing indispensable biological macromolecules [23]. In the present study, we chose the late exponential growth phase bacteria (cultured for $6 \mathrm{~h}$ ) for analysis of proteomics, because SprC reached the maximum amount at this period compared with early and middle exponential growth phases (Figure 1). As expected, the proteomics data provided important clues and the basis for further analysis to uncover new targets of SprC. 


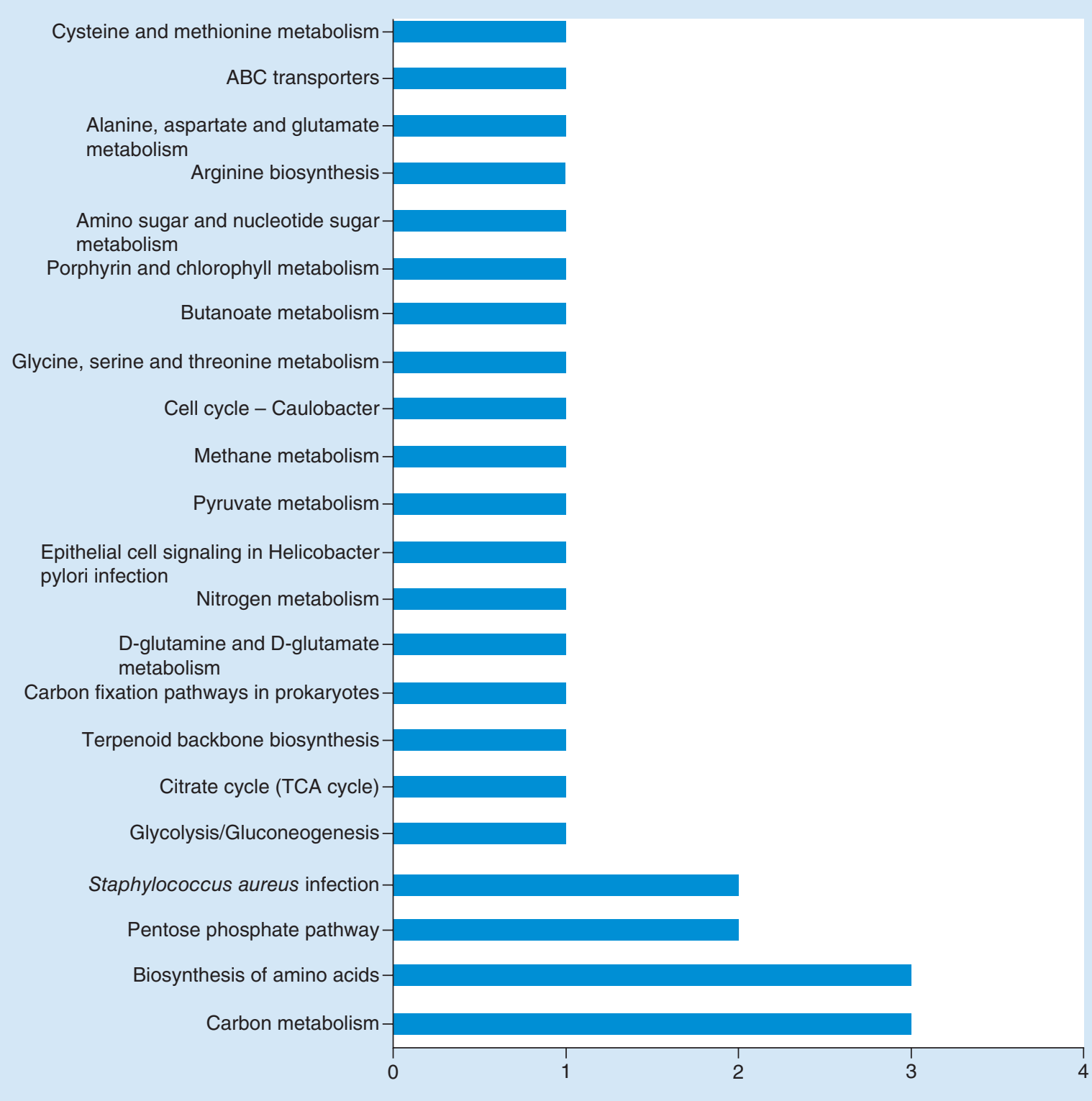

Figure 5. Pathways associated with the differentially expressed proteins determined by Kyoto Encyclopedia of Genes and Genomes analysis. The differentially expressed proteins regulated by SprC have relatively main influence on the pathways related to carbon metabolism, biosynthesis of amino acids, glucose metabolism (pentose phosphate pathway) and Staphylococcus aureus infection. ABC: ATP-binding cassette; TCA: Tricarboxylic acid cycle.

A complex family of virulence determinants of $S$. aureus is the bi-component pore-forming leukocidins which target leukocytes [24]. LukED, one toxin of this family, is mainly responsible for killing leukocyte cells by inducing $\mathrm{Ca}^{2+}$-activated transmembrane pores, thus plays a significant role in the ability of $S$. aureus to avoid host defenses [25-27]. Studies showed that LukED is associated with bloodstream infections, bullous impetigo and postantibiotic diarrhea [28]. Therefore, as shown in this study, reduced expression of the LukED toxin in $S$. aureus, in the presence of $s p r C$, is expected to confer a clinical benefit. However, the specific relationship between SprC and the expression of LukED needs to be investigated further.

Due to the clinical importance of $S$. aureus, identifying the virulence factors, along with their regulatory networks, associated with $S$. aureus pathogenesis has been facilitated by an enormous amount of effort [29]. The expression of virulence genes is usually coordinately regulated by 
RESEARCH ARTICLE Zhao, Hu, Yang et al.

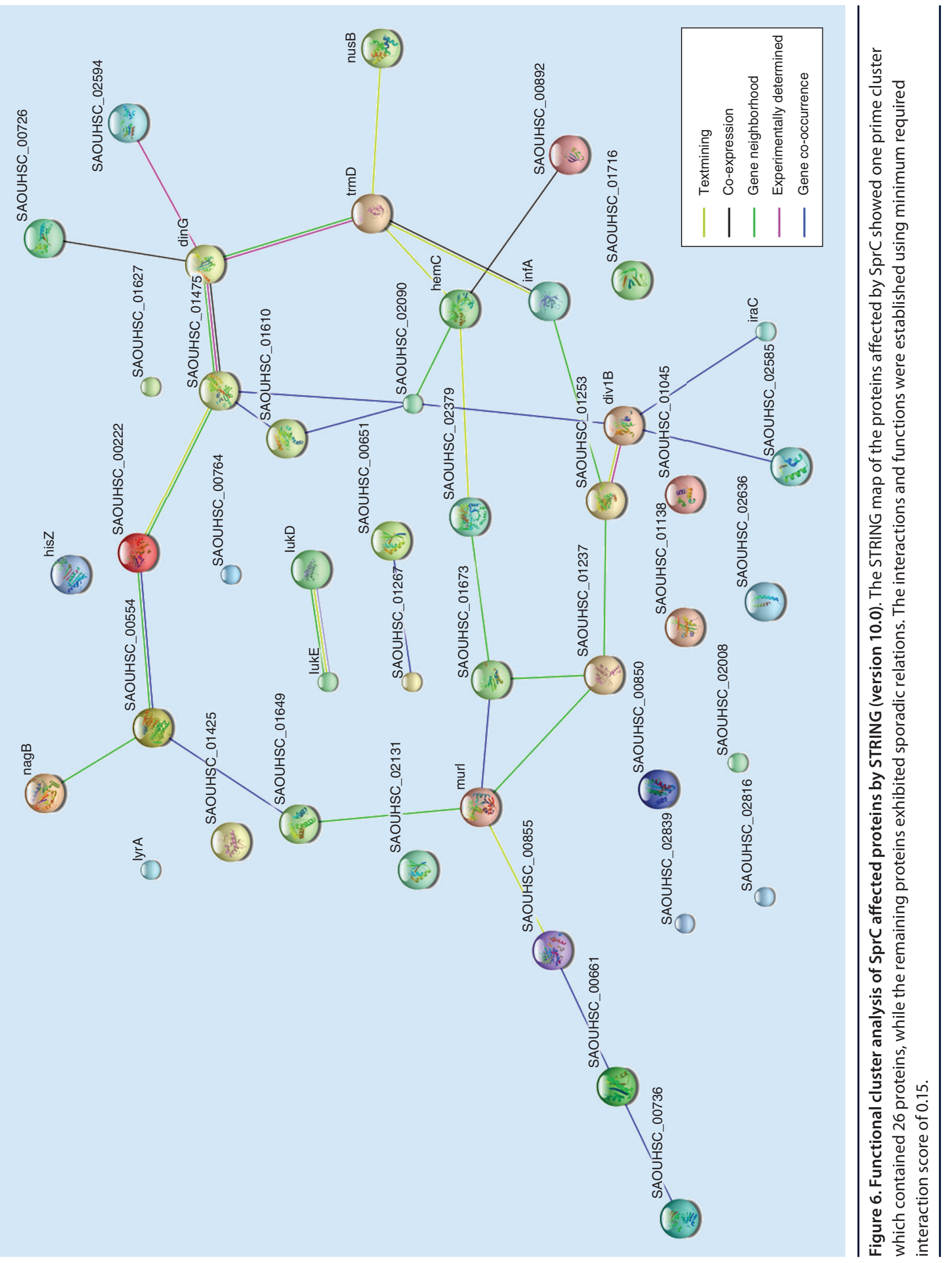


two-component systems and transcription regulators, among which the accessory gene regulator (agr) system and staphylococcal accessory regulator (SarA) are representatives, respectively [3032]. In this study, four differentially expressed proteins (A0A0E1VYJ4, A0A0E1VNW7, A0A0E1VKH8 and A0A0E1VNB1), possibly possessing the functions of DNA binding and transcriptional regulation according to the prediction and analysis of bioinformatics approach, were found. This result indicated that altered expression of the regulatory factors, under the control of SprC, is likely to be the cause of changes of other gene expression in our study.

In the process of infection, the organism faces metabolic and environmental stresses from the host such as reactive oxygen species and lipid peroxides $[33,34]$. If the bacterium has an ineffective response to the injury generated by oxidative stress, it is in danger of amassing harmful mutations, membrane breakdown and cell death [35]. Generation of low-molecular-weight (LMW) thiols is a wise strategy applied by bacteria to maintain its cellular redox balance and soften the effects of reactive oxygen species [34]. In eukaryotes and Gram-negative bacteria, LMW thiol glutathione (GSH) is prevalent [36,37], while in $S$. aureus, bacillithiol (BSH) is the major LMW thiol [38]. The retaining glycosyltransferase (BshA) catalyzes the chemical synthesis of N-acetylglucosaminylmalate (GlcNAc-mal), which is the first committed step in the BSH biosynthesis pathway $[38,39]$. Our proteomics data showed that SprC downregulated the expression of $b \operatorname{sh} A$, suggesting that this sRA may be involved in the oxidative stress response of $S$. aureus. This has been verified in the $S$. aureus Newman strain [13].

By regulating expression of DivIB and SpoIIIE, SprC is involved in S. aureus cell division which is a fundamental process required for successful completion of the bacterial cell cycle. SpoIIIE, a homolog of the Bacillus subtilis (45.9\% identity) along with FtsK, operates in independent pathways for correcting chromosome segregation during cell division $[40,41]$. DivIB is necessary for a molecular checkpoint to guarantee the correct assembly of the bacterial divisome which is a macromolecular machine formed by a variety of proteins [42]. Notably, the growth curve of N315 $\Delta s p r C$ mutant did not obviously change when compared with that of wild-type N315 strain, indicating that the effects of DivIB and SpoIIIE's differential expression in this study were inadequate for influencing the proliferation of $S$. aureus.

NagB (glucosamine-6-phosphate deaminase) has a critical role in the glycolysis pathway and cell-wall biosynthesis [43]. In Streptococcus mutans, the alteration of $\mathrm{NagB}$ expression can affect the virulence of the bacteria [44], but the corresponding role in $S$. aureus remains unclear. Another protein affected by $\mathrm{SprC}$ is undecaprenyl diphosphate synthase, which is crucial for peptidoglycan biosynthesis and consequently influences bacterial cell growth. Because of this characteristic, undecaprenyl diphosphate synthase has become a target for developing new antibiotics [45]. Therefore, SprC may play a significant role in cell-wall biosynthesis by regulating the target proteins mentioned above.

Among the differentially expressed proteins, LyrA (A0A0E1VXW4) has been revealed to be associated with resisting lysostaphin that is secreted by Staphylococcus simulans with bacteriolytic activity against staphylococci [46]. This potentially extends the impacts of SprC in S. aureus.

Many proteins in bacteria including $S$. aureus are expressed as polycistron. In the present study, some of the genes for differentially expressed proteins were clustered as operon; however, other member proteins of the same operon were not identified. For instance, in the operon expressing proteins SA1119, SA1120, SA1121, SA1122 and SA1123, only SA1119 (FtsK/SpoIII E family protein) was detected in proteomics study. This phenomenon has also been found in previous studies $[47,48]$. The potential explanations may be diverse modification in transcriptional and translational level, some intracellular chemical reaction and/or the presence of protease affecting the amount of protein.

\section{Conclusion}

SprC could be related to the expression of a variety of proteins with a direct or indirect mechanism based on our research. However, these affected proteins were rarely enriched in a few concentrated pathways, biological processes and molecular functions, which indicated that SprC regulated the various aspects of gene expression through base-pairing interactions, and sRNAs exerted complicated and significant roles in the regulatory networks of $S$. aureus. Further studies will be necessary to explore the underlying regulatory mechanisms to confirm the key role of SprC in metabolism and pathogenesis of $S$. aureus. 


\section{Acknowledgements}

The authors would like to thank M Li for the gift of $p K O R 1$.

Financial \& competing interests disclosure

This work was supported by grants from the National Natural Science Foundation of China (81371872) and Natural Science Foundation, Science and Technology Commission of Shanghai (12ZR1425000). The authors have no other relevant affliations or financial involvement with any organization or entity with a financial interest in or financial conflict with the subject matter or materials discussed in the manuscript apart from those disclosed.

No writing assistance was utilized in the production of this manuscript.

\section{Ethical conduct of research}

The authors state that they have obtained appropriate institutional review board approval or have followed the principles outlined in the Declaration of Helsinki for all human or animal experimental investigations. In addition, for investigations involving human subjects, informed consent has been obtained from the participants involved.

\section{Open access}

This work is licensed under the Creative Commons Attribution 4.0 License. To view a copy of this license, visit http://creativecommons.org/licenses/by/4.0/

\section{SUMMARY POINTS}

- SprC shows variations of expression at different growth phases of Staphylococcus aureus N315, among which the amount of SprC reaches the highest level in the stationary phase bacteria.

- A total of 44 proteins are found to be significantly affected by SprC, including eight upregulated and 36 downregulated molecules.

- Bioinformatic analysis shows that the proteins affected by SprC are mainly related to metabolic and cellular process, biological regulation and catalytic activity of S. aureus.

\section{References}

Papers of special note have been highlighted as: - of interest; $\bullet$ of considerable interest

1 Uhlemann AC, Otto M, Lowy FD et al. Evolution of community- and healthcareassociated methicillin-resistant Staphylococcus aureus. Infect. Genet. Evol. 21(1), 563-574 (2014).

2 Bronner S, Monteil H, Prevost G. Regulation of virulence determinants in Staphylococcus aureus: complexity and applications. FEMS Microbiol. Rev. 28(2), 183-200 (2004).

3 Guillet J, Hallier M, Felden B. Emerging functions for the Staphylococcus aureus RNome. PLoS Pathog. 9(12), e1003767 (2013).

4 Beisel CL, Storz G. Base pairing small RNAs and their roles in global regulatory networks. FEMS Microbiol. Rev. 34(5), 866-882 (2010).

5 Sassi M, Augagneur Y, Mauro T et al. SRD: a Staphylococcus regulatory RNA database. RNA 21(5), 1005-1017 (2015).

6 Kathirvel M, Buchad H, Nair M. Enhancement of the pathogenicity of Staphylococcus aureus strain Newman by a small noncoding RNA SprX1. Med. Microbiol. Immunol. 205(6), 563-574 (2016).

- Demonstrates the role of small regulatory RNA (sRNA) SprX in the pathogenicity of Staphylococcus aureus Newman.
7 Abu-Qatouseh LF, Chinni SV, Seggewiss J et al. Identification of differentially expressed small non-protein-coding RNAs in Staphylococcus aureus displaying both the normal and the small-colony variant phenotype. J. Mol. Med. (Berl) 88(6), 565-575 (2010).

8 Beaume M, Hernandez D, Farinelli L et al. Cartography of methicillin-resistant $S$. aureus transcripts: detection, orientation and temporal expression during growth phase and stress conditions. PLoS ONE 5(5), e10725 (2010).

9 Pichon C, Felden B. Small RNA genes expressed from Staphylococcus aureus genomic and pathogenicity islands with specific expression among pathogenic strains. Proc. Natl Acad. Sci. USA 102(40), 14249-14254 (2005).

10 Eyraud A, Tattevin P, Chabelskaya S et al. A small RNA controls a protein regulator involved in antibiotic resistance in Staphylococcus aureus. Nucleic Acids Res. 42(8), 4892-4905 (2014).

- Describes the influence of sRNA SprX on antibiotic resistance of $S$. aureus.

11 Sayed N, Jousselin A, Felden B. A cis-antisense RNA acts in trans in Staphylococcus aureus to control translation of a human cytolytic peptide. Nat. Struct. Mol. Biol. 19(1), 105-112 (2011).
- Provides evidence that the $c i s$-encoded sRNA SprA1/SprA1 ${ }_{\mathrm{AS}}$ functions in trans.

12 Chabelskaya S, Gaillot O, Felden B. A Staphylococcus aureus small RNA is required for bacterial virulence and regulates the expression of an immune-evasion molecule. PLoS Pathog. 6(6), e1000927 (2010).

- Describes the regulatory mechanism of Sbi and the enhance of the virulence of $S$. aureus by sRNA SprD.

13 Le Pabic H, Germain-Amiot N, Bordeau V et al. A bacterial regulatory RNA attenuates virulence, spread and human host cell phagocytosis. Nucleic Acids Res. 43(19), 9232-9248 (2015).

- Demonstrates that sRNA SprC attenuates the virulence of $S$. aureus Newman.

14 Kreiswirth BN, Löfdahl S, Betley MJ et al. The toxic shock syndrome exotoxin structural gene is not detectably transmitted by a prophage. Nature 305(5936), 709-712 (1983).

15 Kuwaharaarai K, Kondo N, Hori S et al. Suppression of methicillin resistance in a mecA-containing pre-methicillin-resistant Staphylococcus aureus strain is caused by the mecI-mediated repression of PBP 2 production. Antimicrob. Agents Chemother. 40 (12), 2680-2685 (1996).

16 Bae T, Schneewind O. Allelic replacement in Staphylococcus aureus with inducible 
counter-selection. Plasmid 55(1), 58-63 (2006).

17 Schneewind O, Mihaylova-Petkov D, Model P. Cell wall sorting signals in surface proteins of Gram-positive bacteria. EMBO J. 12(12), 4803-4811 (1993).

18 UniProt. www.uniprot.org

19 Blast2GO Version 4.0. www.blast2go.com

20 Moriya Y, Itoh M, Okuda S et al. KAAS: an automatic genome annotation and pathway reconstruction server. Nucleic Acids Res. 35 , W182-W185 (2007).

21 Ross PL, Huang YN, Marchese JN et al. Multiplexed protein quantitation in Saccharomyces cerevisiae using amine-reactive isobaric tagging reagents. Mol. Cell Proteomics 3(12), 1154-1169 (2004).

22 Fechter P, Caldelari I, Lioliou E et al. Novel aspects of RNA regulation in Staphylococcus aureus. FEBS Lett. 588(15), 2523-2529 (2014).

- Reviews the role of sRNA in regulating pathogenesis, antibiotic resistance and host-bacteria interplays.

23 Rolfe MD, Rice CJ, Lucchini S et al. Lag phase is a distinct growth phase that prepares bacteria for exponential growth and involves transient metal accumulation. J. Bacteriol. 194(3), 686-701 (2012).

24 Balasubramanian D, Ohneck EA, Chapman J et al. Staphylococcus aureus coordinates leukocidin expression and pathogenesis by sensing metabolic fluxes via RpiRc. MBio 7(3), e00818-16 (2016).

25 Gravet A, Colin DA, Keller D et al. Characterization of a novel structural member, LukE-LukD, of the bi-component staphylococcal leucotoxins family. FEBS Lett. 436(2), 202-208 (1998).

26 Gravet A, Couppie P, Meunier O et al. Staphylococcus aureus isolated in cases of impetigo produces both epidermolysin A or B and LukE-LukD in $78 \%$ of 131 retrospective and prospective cases. J. Clin. Microbiol. 39(12), 4349-4356 (2001).

27 Yoong P, Torres VJ. The effects of Staphylococcus aureus leukotoxins on the host: cell lysis and beyond. Curr. Opin. Microbiol. 16(1), 63-69 (2013).

28 Nocadello S, Minasov G, Shuvalova L et al. Crystal structures of the components of the Staphylococcus aureus leukotoxin ED. Acta Crystallogr. D Struct. Biol. 72(Pt 1), 113-120 (2016).

29 Dunman PM, Murphy E, Haney S et al. Transcription profiling-based identification of Staphylococcus aureus genes regulated by the agr and/or sarA loci. J. Bacteriol. 183(24), 7341-7353 (2001).

30 Novick RP. Autoinduction and signal transduction in the regulation of staphylococcal virulence. Mol. Microbiol. 48(6), 1429-1449 (2003).

31 Koenig RL, Ray JL, Maleki SJ et al. Staphylococcus aureus Agra binding to the RNAIII-agr regulatory region. J. Bacteriol. 186(22), 7549-7555 (2004).

32 Cheung AL, Koomey JM, Butler CA et al. Regulation of exoprotein expression in Staphylococcus aureus by a locus (sar) distinct from agr. Proc. Natl Acad. Sci. USA 89(14), 6462-6466 (1992)

33 Iyer GY, Islam MF, Quastel JH. Biochemical aspects of phagocytosis. Nature 192(4802), 535-541 (1961).

34 Posada AC, Kolar SL, Dusi RG et al. Importance of bacillithiol in the oxidative stress response of Staphylococcus aureus. Infect. Immun. 82(1), 316-332 (2014).

35 Weber H, Engelmann S, Becher D et al. Oxidative stress triggers thiol oxidation in the glyceraldehyde-3-phosphate dehydrogenase of Staphylococcus aureus. Mol. Microbiol. 52(1), 133-140 (2004).

36 Upton H, Newton GL, Gushiken M et al. Characterization of BshA, bacillithiol glycosyltransferase from Staphylococcus aureus and Bacillus subtilis. FEBS Lett. 586(7), 1004-1008 (2012).

37 Lushchak VI. Glutathione homeostasis and functions: potential targets for medical interventions. J. Amino Acids 2012, 736837 (2012).

38 Newton GL, Rawat M, La Clair JJ et al. Bacillithiol is an antioxidant thiol produced in Bacilli. Nat. Chem. Biol. 5(9), 625-627 (2009).
39 Gaballa A, Newton GL, Antelmann $\mathrm{H}$ et al. Biosynthesis and functions of bacillithiol, a major low-molecular-weight thiol in Bacilli. Proc. Natl Acad. Sci. USA 107(14), 64826486 (2010).

40 Yu W, Herbert S, Graumann PL et al. Contribution of SMC (structural maintenance of chromosomes) and SpoIIIE to chromosome segregation in Staphylococci. J. Bacteriol. 192(15), 4067-4073 (2010).

41 Veiga H, M GP. Staphylococcus aureus requires at least one FtsK/SpoIIIE protein for correct chromosome segregation. Mol. Microbiol. 103(3), 504-517 (2017).

42 Bottomley AL, Kabli AF, Hurd AF et al. Staphylococcus aureus DivIB is a peptidoglycan-binding protein that is required for a morphological checkpoint in cell division. Mol. Microbiol. 94(5), 1041-1064 (2014).

43 Komatsuzawa H, Fujiwara T, Nishi $\mathrm{H}$ et al. The gate controlling cell wall synthesis in Staphylococcus aureus. Mol. Microbiol. 53(4), 1221-1231 (2004).

44 Kawadamatsuo M, Oogai Y, Komatsuzawa H. Sugar allocation to metabolic pathways is tightly regulated and affects the virulence of Streptococcus mutans. Genes 8(1), 11 (2016).

45 Sinko W, Wang Y, Zhu W et al. Undecaprenyl diphosphate synthase inhibitors: antibacterial drug leads. J. Membr. Biol. 57(13), 5693-5701 (2014).

46 Gründling A, Missiakas DM, Schneewind O. Staphylococcus aureus mutants with increased lysostaphin resistance. J. Bioact. 188(17), 6286-6297 (2006).

47 Cordwell SJ, Larsen MR, Cole RT et al. Comparative proteomics of Staphylococcus aureus and the response of methicillinresistant and methicillin-sensitive strains to Triton X-100. Microbiology 148(Pt 9), 2765-2781 (2002).

48 Drummelsmith J, Winstall E, Bergeron MG et al. Comparative proteomics analyses reveal a potential biomarker for the detection of vancomycin-intermediate Staphylococcus aureus strains. J. Proteome Res. 6(12), 4690-4702 (2007). 